\title{
ZC3H15 promotes glioblastoma progression through regulating EGFR stability
}

\author{
Jianbing Hou ${ }^{1,2}$, Minghao Xu $\mathbb{D}^{1,2}$, Hongyu Gu${ }^{1,2}$, Dakun Pei ${ }^{1,2}$, Yudong Liu ${ }^{1,2}$, Pan Huang ${ }^{1,2}$, Hongbo Chang ${ }^{1,2}$ and \\ Hongjuan Cui iD ${ }^{1,2 \bowtie}$
}

(c) The Author(s) 2022

Zinc finger $\mathrm{CCCH}$-type containing 15 (ZC3H15), a highly conserved protein involved in several cellular processes, which was responsible for tumorigenesis and may be a promising marker in myeloid leukemia (AML) and hepatocellular carcinoma (HCC). However, little is known about the biological significance and molecular mechanisms of ZC3H15 in GBM. In this study, we revealed that ZC3H15 was overexpressed in GBM and high ZC3H15 expression was associated with poor survival of patients with GBM. We found that $\mathrm{ZC} 3 \mathrm{H} 15$ promoted the proliferation, migration, invasion, and tumorigenesis of GBM cells by activating the EGFR signaling pathway. We also revealed that $\mathrm{ZC} 3 \mathrm{H} 15$ reduced EGFR ubiquitination, which was responsible for EGFR protein stabilization. In addition, we demonstrated that $\mathrm{ZC} 3 \mathrm{H} 15$ inhibited the transcription of $\mathrm{CBL}$, which was an E3 ubiquitin ligase for EGFR proteasomal degradation. And silencing of $C B L$ could partly abrogate the inhibitory effects on cell proliferation, migration, and invasion of GBM cells induced by $\mathrm{ZC} 3 \mathrm{H} 15$ knockdown. Thus, our research revealed the important roles of ZC3H15 in GBM development and provided a brand-new insight for improving the treatment of GBMs.

Cell Death and Disease (2022)13:55; https://doi.org/10.1038/s41419-021-04496-9

\section{INTRODUCTION}

Glioblastoma which is known as GBM, classified as the WHO IV, possesses the most aggressive ability. The prognosis and survival rate are poor and the median survival time of GBM patients is 14.6 months $[1,2]$. Due to its high infiltrative nature, traditional maximum safety resection, radiotherapy and chemotherapy cannot completely remove the intracranial tumor tissue, and eventually lead to recurrence [3]. Two to three people in 100,000 in Europe and North America developed GBM, and of those affected, $90 \%$ died within three years [4]. Hence, it is great urgent to find out new treatments for effective GBM therapy.

Zinc finger $\mathrm{CCCH}$-type containing $15(\mathrm{ZC} 3 \mathrm{H} 15)$ also known as DFRP1, a highly conserved gene located at 2q32.1 [5, 6]. ZC3H15 was demonstrated to ortholog with immediate early response erythropoietin 4 (LEREPO4) in mice and induced by erythropoietin [7]. Both ZC3H15 (DFRP1) and DFRP2 possess the DRG family regulatory protein domain, which is pivotal in the interaction of DRG1 and DRG2 [7]. This indicates that ZC3H15 may involve in signaling transduction. Gianni et al. demonstrated that $\mathrm{ZC} 3 \mathrm{H} 15$ regulated the NF-KB signaling pathway by interacting with TRAF-2 [8]. Moreover, $\mathrm{ZC} 3 \mathrm{H} 15$ also contains the tandem repeat $\mathrm{CCCH}$ zinc finger (TZF) domain, which indicates that it may possess the ability to transcriptional regulation and RNA metabolism $[9,10]$. At present, there are few studies on $\mathrm{ZC} 3 \mathrm{H} 15$, however, the functions of $\mathrm{ZC} 3 \mathrm{H} 15$ protein were relatively rich, which have yet to discover and explore.

Casitas B-lineage (CBL) is commonly expressed in cells and belongs to the RING family, contains the Ring finger domain and tyrosine kinase-binding domain in N-terminal. It has been shown that $\mathrm{CBL}$ possesses both signaling transduction activity and E3 ubiquitin ligase activity $[10,11]$. Indeed, recent studies reported that CBL enhanced the activity of immune cells by reducing PD-L1 expression via the CBL-STAT-AKT-ERK signaling pathway [12]. And CBL played as an E3 ubiquitin ligase to inhibit receptor tyrosine kinase RTKs signaling pathway to further suppress tumor proliferation [13]. Interestingly, CBL protein acts as a tumor suppressor in most cancers, such as nonsmall cell lung cancer, GBM, and gastric cancer. However, CBL promotes tumorigenesis in resectable pancreatic ductal adenocarcinoma $[12,14,15]$. Due to the multi-function of $C B L$, it is worth further studying the detailed mechanisms.

The metastasis and proliferation of numerous cancers are driven by epidermal growth factor receptor (EGFR), which is a member of the ErbB family of receptor tyrosine kinases (RTK). Amplification of the EGFR gene and frequent mutations in the EGFR tyrosine kinase domain have recently been demonstrated in cancer patients [16]. Due to the central role of EGFR in cellular progress, the EGFR signaling pathway has become one of the most well-studied signaling pathways in human tumors [17]. As a cross-membrane protein, EGFR is involved in cell to cell communication, cell fate determination, migration, proliferation, and invasion [18-20]. It can also be the substrate for enzymes or the upstream of the signaling pathways. For instance, EGFR promotes tumorigenesis through the EGFR-PI3K/AKT-mTOR-HIF1a signaling pathway. While HIF1 $a / H I F 2 a$ also interacts with EGFR to form a positive feedback [21]. Moreover, in our previous study, the E3 ubiquitin ligase CHIP,

\footnotetext{
${ }^{1}$ State Key Laboratory of Silkworm Genome Biology, Southwest University, 400716 Chongqing, China. ${ }^{2}$ Cancer Center, Reproductive Medicine Center, Medical Research Institute, Southwest University, 400716 Chongqing, China. ${ }^{凶}$ email: hongjuan.cui@gmail.com

Edited by Dr Francesca Bernassola
}

Received: 25 June 2021 Revised: 8 November 2021 Accepted: 16 November 2021

Published online: 13 January 2022 
degraded EGFR protein which could be aborted by an oncoprotein CSN6 [22]. EGFR activation also combines with RTKs heterodimerization or homodimerization and further leads to the activation of various signaling pathways including the Ras-ERK and PI3K-AKT signaling pathways [23-25]. Small molecular inhibitor erlotinib has been discovered recently, it suppresses tumor growth by inhibiting the activation of EGFR. However, inhibiting EGFR in tumors in vivo by erlotinib may not efficient [26-28]. This indicated that drug therapy alone cannot cure tumors completely, and combination therapy will become the trend.

In this study, we found that $\mathrm{ZC} 3 \mathrm{H} 15$ was overexpressed in GBM and high $\mathrm{ZC} 3 \mathrm{H} 15$ expression was associated with poor survival of GBM patients. $\mathrm{ZC} 3 \mathrm{H} 15$ promoted the proliferation, migration, invasion, and tumorigenesis of GBM cells by reducing EGFR ubiquitination degradation. In addition, we found that $\mathrm{ZC} 3 \mathrm{H} 15$ elevated the protein stability of EGFR by inhibiting CBL transcription. Thus, our research revealed the important roles of $\mathrm{ZC} 3 \mathrm{H} 15$ in GBM development and provided a brand-new insight for improving the prognosis for GBM patients.

\section{MATERIALS AND METHODS}

\section{Cell lines, reagents, and antibodies}

Human GBM cell lines (LN-229, U-251 MG, A172, U-118 MG, and U-87 MG) and normal astroglia cells (SVGP12) were obtained from American Type Culture Collection (ATCC, USA), and all tests were negative for mycoplasma. Cells were cultured by DMEM with $10 \%$ fetal bovine serum and $1 \%$ Penicillin-Streptomycin solution in $37^{\circ} \mathrm{C}$ and $5 \% \mathrm{CO}_{2}$ incubator. The DMEM media, FBS, and antibiotics were obtained from Thermo Fisher Scientific (MA, USA).

Reagents used in this passage including Cycloheximide (CHX) (Merck, America, CAS:66-81-9), proteasome inhibitor (MG-132) (MCE, China, CAS: 133407-82-6), and Erlotinib (MCE, China, CAS: 183319-69-9).

Antibodies used in this passage including anti-ZC3H15 (Novus Biologicals, USA, CAS: NBP1-81312), anti-EGFR (Cell Signaling Technology, USA, CAS: 4267), anti-p-EGFR (Cell Signaling Technology, USA, CAS: 3777), anti-AKT (Cell Signaling Technology, USA, CAS: 4685), anti-p-AKT (Cell Signaling Technology, USA, CAS: 4060), anti-CBL (Proteintech, China, CAS: 25818-1-AP), anti-PARK2 (Proteintech, China, CAS: 14060-1-AP), anti-STUB1 (Proteintech, China, CAS: 55430-1-AP), anti-Tubulin (Proteintech, China, CAS: 11224-1-AP), anti-Flag (Cell Signaling Technology, USA, CAS: 14793), anti-HA (Proteintech, China, CAS: 51064-2-AP), Anti-actin (Cell Signaling Technology, USA, CAS: 3700), antiPaxillin (Proteintech, China, CAS: 10029-1-lg), anti- $\beta$-catenin (Cell Signaling Technology, USA, CAS: 8480), anti-ZEB1 (Proteintech, China, CAS: 21544-1-AP), anti-Slug (Proteintech, China, CAS: 12129-1-AP), anti-N-cadherin (Proteintech, China, CAS: 22018-1-AP), anti-E-cadherin (Proteintech, China, CAS: 20874-1AP), and anti-BrdU (Abcam, USA, CAS: ab6326).

\section{Database analysis and patient tumor samples}

The gene expression data of $\mathrm{ZC} 3 \mathrm{H} 15$ was downloaded and analyzed from the CGGA database (http://www.cgga.org.cn/), GlioVis database (http:// gliovis.bioinfo.cnio.es/), and TCGA database (https://www.cancer.gov/ about-nci/organization/ccg/research/structural-genomics/tcga). Cutoff separating was based on the expression level of $\mathrm{ZC} 3 \mathrm{H} 15$, Kaplan-Meier analysis was plotted by CGGA, GlioVis, and R2 database (http://hgserver1. amc.nl/cgi-bin/r2/main.cgi).

Tumor samples were obtained from Chaoying Biotechnology Co., Ltd. (Henan, China). Tissue analysis was approved by the Ethics Committee of Southwest University of China. All the patients provided written informed consent to participate.

\section{Transfection and Infection}

shZC $3 \mathrm{H} 15$, shCBL and control sequences were recombined into pLKO.1puro plasmid, and the sequences were listed as below:

Scramble: AGCACACTAGAACCATGTGAA

shZC3H15-1: GCAAGAGATGAAGAACTTGAA

shZC3H15-2: CAGATCCCAAGTCTGTAGTAT

shZC3H15-3: CCTAGAATCAACAGGATGTTI

shCBL-1: GACAAGAAGATGGTGGAGAAG

shCBL-2: CCCTCACAATAAACCTCTCTT

shCBL-3: CCAGTGAGTTGGGAGTTATTA
Flag-tagged full length of $\mathrm{ZC} 3 \mathrm{H} 15$ and EGFR recombined into the $\mathrm{pCDH}$ CMV-MCS-EF1-Puro plasmid (Youbio, Hunan, China).

For transfection, lipofectamine2000 (Thermo, USA, CAS:11668019) and specific plasmids were added into the 6 -well plate. The medium was changed after 6-8 h. Cells were retrieved after $48 \mathrm{~h}$.

For infection, lentivirus was produced by HEK-293 FT cells. After two times of infection, the medium was refreshed and puromycin was added to screen the cells that are infected.

\section{Western Blot Analysis and Immunoprecipitation}

For the western blot assay, cells were retrieved and lysed on ice by RIPA lysis buffer (Beyotime, China). The supernatant was collected after centrifuge $12,000 \mathrm{rpm}$ at $4{ }^{\circ} \mathrm{C}$ for $10 \mathrm{~min}$. The protein was boiled with loading buffer at $96^{\circ} \mathrm{C}$, followed by SDS-PAGE and transmembrane (Bio-Rad, USA). Secondary antibody was incubated after finishing the incubation of primary antibody. The membrane was exposed in the gel imaging system (Qinxiang, China)

For the immunoprecipitation assay, cells were retrieved and lysed on ice by IP lysis buffer (Beyotime, China), The supernatant was collected after centrifuge $12,000 \mathrm{rpm}$ at $4^{\circ} \mathrm{C}$ for $10 \mathrm{~min}$, and specific antibodies were added. After $12 \mathrm{~h}$ combination, Protein A + G Agarose (Beyotime, China) was added and rotary table for $4 \mathrm{~h}$. Agarose was washed 5 times with PBS followed by loading buffer boiling. Then Western Blot assay was performed.

\section{BrdU and Immunohistochemistry staining (IHC)}

For the BrdU assay, $2 \times 10^{4}$ cells were seeded into the 24-well plate. BrdU was added into the well after the cell adheres to the wall and cultured for $4 \mathrm{~h}$, followed by $4 \%$ PFA immobilization, $0.2 \%$ Triton $\mathrm{X}-100$

Table 1. Primer pairs for real-time PCR and ChIP assays.

Primer pairs for real-time $P C R$

ZC3H15-F

AACAAAATCCACGTCAGGTAGC

$\mathrm{ZC} 3 \mathrm{H} 15-\mathrm{R}$ TGCACATACTACAGACTTGGGA

EGFR-F

EGFR-R AGGCACGAGTAACAAGCTCAC

CBL-F ATGAGGACATAACCAGCCACC

CBL-R TAGGCGAAACCTAACCAAACTG

PARK2-F AGAGTCCACTTGGAAAGATTCCT

PARK2-R GTGTTTGTCAGGTTCAACTCCA

STUB1-F GAAAATCACACGCAACTGGTC STUB1-R AGCAGGGCAATCGTCTGTTC CAAGGCCCGGTTGGTGTAATA

Primer pairs for ChIP assays

CBL-2589/-2440-F

CBL-2589/-2440-R

CTGTACTCCAGCCTGGGTGAC

CBL-2279/-2005-F

CBL-2279/-2005-R

CBL-1821/-1559-F

CBL-1821/-1559-R

CBL-1640/-1519-F

CBL-1640/-1519-R

CBL-1150/-949-F

CBL-1150/-949-R

CBL-739/-565-F

CBL-739/-565-R

CBL-667/-378-F

CBL-667/-378-R

CBL 79/318-F

CBL 79/318-R

GGCTGAGCGACAAGAGTGAGA
GGCCAAGGATGGTCTCGAT
CCTTATTCCATCTGCCTGAAGTAT
GGTGGCGGGCACTTGTAA
CCCATTGCCTCGGGAATAA
GTACCAGGGAGTAGTATAAAACTACAAGG
GTATAGTTCAGACAGCATCGCAAAA
GAAGGCGGAACTGATACTGACA
GCCCAGGGAACAGAAATGC
GTCAAAGGGCCTGGAAGAAGA
GGGAGGATGGTGGGAGAAAA
GGGCCGCAGCATTCATATT
CGCAGTAGCCAGAAACCAAGA
TCCTTCACGCCCTGCTTCT
GCACTTCTCCACCATCTTCTTGT


punching, $2 \mathrm{M} \mathrm{HCl}$ solution uncoiling. BrdU primary antibody incubated at $4{ }^{\circ} \mathrm{C}$ overnight followed by Alexa Fluor 594 secondary antibody incubation. DAPI was stained before microscope examination.

For the IHC staining, the tissue slides were incubated with specific primary antibodies overnight at $4{ }^{\circ} \mathrm{C}$ after deparaffinization, rehydration, hydrogen peroxide treatment, citrate buffer for antigen retrieval, and goat serum blocking. Then slides were incubated with horseradish peroxidaselinked secondary antibody. Diaminobenzidine treatment for visualizing followed by hematoxylin counterstain.

\section{Ubiquitination assay}

Flag-tagged $\mathrm{ZC} 3 \mathrm{H} 15$ and $\mathrm{HA}$-tagged Ub plasmids were co-transfected into 293 FT cells, the remaining steps are the same with transfection assay and co-immunoprecipitation assay except the MG-132 was added $8 \mathrm{~h}$ before cells were retrieved.

\section{Protein turnover assay}

Specific plasmids were transfected into the cells followed by $\mathrm{CHX}$ addition at a concentration of $100 \mu \mathrm{g} / \mathrm{ml}$, cells were harvested in a time gradient and followed by Western Blot analysis.

\section{ChIP assay and qRT-PCR}

Cells were transfected with CBL promoter truncated plasmid and Flagtagged ZC3H15 plasmid and lysed on the ice with SDS lysis buffer after two days. After centrifugation, the supernatant was obtained and the anti-Flag antibody was added. The remaining steps were followed by protocols in ChIP Assay Kit (Beyotime, China). SYBR qPCR SuperMix Plus was used for qRT-PCR (Novoprotein, China). The primer pairs are shown in Table 1.

Total mRNA of cells was extracted by the TRIzol method. mRNA was reverse transcripted into CDNA by 1st Strand cDNA Synthesis SuperMix for qPCR (YEASEN, China). And the CDNA was used to perform qRT-PCR.

\section{MTT Assay}

$1 \times 10^{3}$ cells were seeded into the 96-well plate. MTT was added and incubated for $2 \mathrm{~h}$ and then removed the medium, added $200 \mu \mathrm{L}$ DMSO. $560 \mathrm{~nm}$ absorbency was measured by microplate reader. Repeat the above steps for 6 days. Triplicate was conducted in each sample.

\section{Migration and invasion analysis}

Cells were seeded into transwell (Corning, USA) with $100 \mu \mathrm{l}$ serum-free medium, and $500 \mu \mathrm{l}$ complete medium was added into the lower chamber.
A

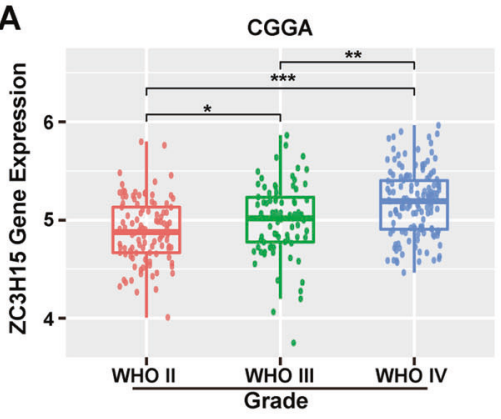

B

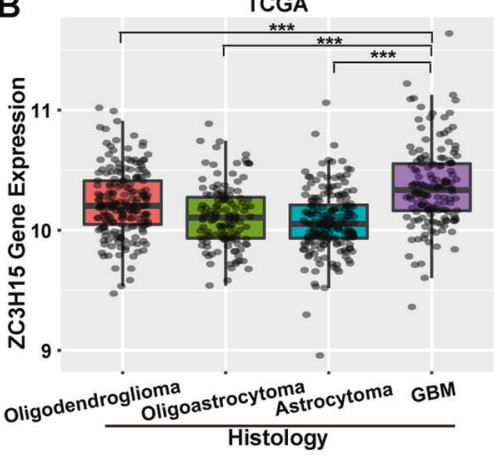

C

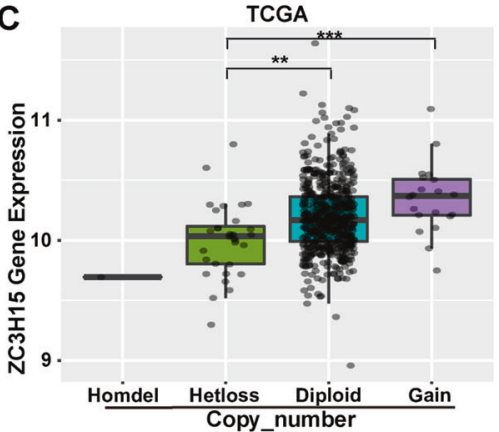

D

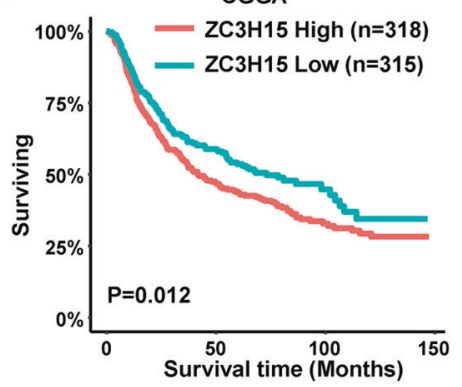

E

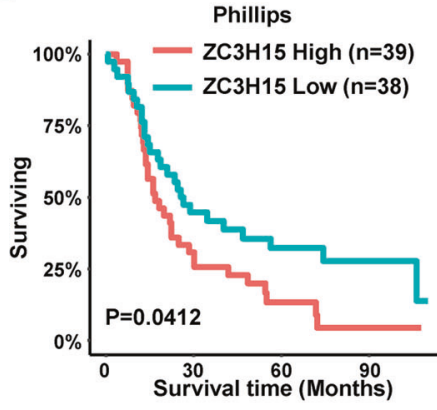

$\mathbf{F}$

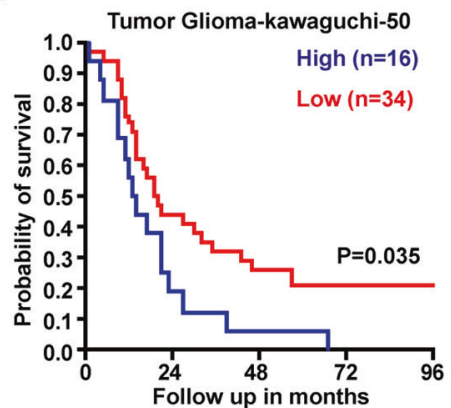

G
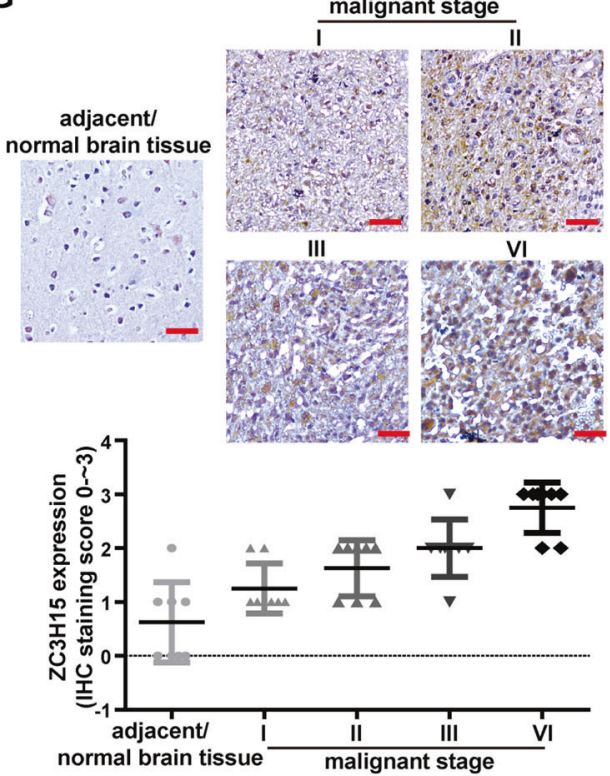

H

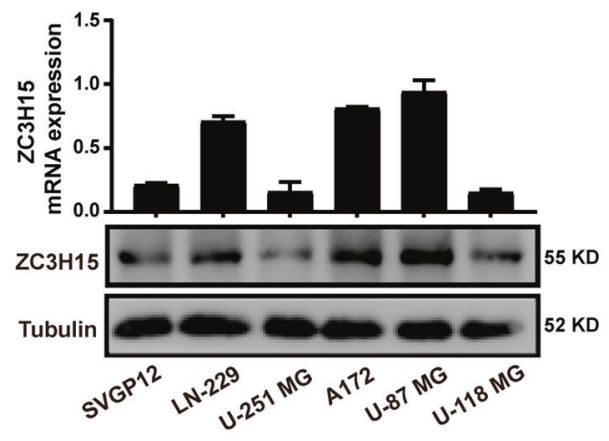

Fig. $1 \mathrm{ZC} 3 \mathrm{H} 15$ is commonly upregulated in GBM and correlates with poor prognosis. A, B ZC3H15 gene expression was obtained from TCGA and CGGA database. Box plot of ZC3H15 expression levels in Grade and Histology glioma set with the log-rank test $P$-values indicated. C Box plot of $\mathrm{ZC} 3 \mathrm{H} 15$ expression levels in Copy number glioma set with the log-rank test $P$-values indicated. D-F The correlation between $\mathrm{ZC} 3 \mathrm{H} 15$ expression levels and survival rate were obtained from TCGA, Phillips, and Tumor Glioma-kawaguchi-50 and were performed through Kaplan-Meier (K-M) analysis, the log-rank test $P$-value was indicated. G Representative immunohistochemistry staining of ZC3H15 expression level in normal tissue and different grades of GBM. And analysis based on the staining of normal tissue (eight samples) and different grades of GBM (eight samples of each group). $\mathbf{H}$ The protein and mRNA expression profile of ZC3H15 was examined by qRT-PCR and Western Blot assay. All data were expressed as mean \pm SD. Student's $t$ test was performed to analyzed significance. ${ }^{*} P<0.05,{ }^{* *} P<0.01,{ }^{* * *} P<0.001$. 
Table 2. Correlation of $\mathrm{ZC} 3 \mathrm{H} 15$ expression with clinicopathological variables in CGGA data sets.

\begin{tabular}{|c|c|c|c|c|c|c|}
\hline \multicolumn{2}{|c|}{ Clinicopathological features } & \multirow[t]{2}{*}{ Cases } & \multicolumn{2}{|c|}{ ZC3H15 expression } & \multirow[t]{2}{*}{$\boldsymbol{F}$} & \multirow[t]{2}{*}{$\boldsymbol{P}$} \\
\hline & & & Low & High & & \\
\hline Age & $\leqq 40$ & 140 & 84 & 56 & 0.271 & 0.603 \\
\hline \multirow[t]{2}{*}{ Gender } & Male & 180 & 94 & 86 & \multirow[t]{2}{*}{0.791} & \multirow[t]{2}{*}{0.375} \\
\hline & Female & 121 & 58 & 63 & & \\
\hline \multirow[t]{2}{*}{ Grade } & WHO II & 117 & 66 & 51 & \multirow[t]{2}{*}{8.335} & \multirow[t]{2}{*}{$<0.001$} \\
\hline & WHO IV & 124 & 48 & 76 & & \\
\hline \multirow[t]{2}{*}{ IDH mutation status } & Mutation & 134 & 78 & 56 & \multirow[t]{2}{*}{1.372} & \multirow[t]{2}{*}{0.242} \\
\hline & Wildtype & 165 & 73 & 92 & & \\
\hline \multirow[t]{2}{*}{ 1p19q_Codeletion_status } & Non-cadel & 76 & 38 & 38 & \multirow[t]{2}{*}{1.846} & \multirow[t]{2}{*}{0.178} \\
\hline & Cadel & 16 & 5 & 11 & & \\
\hline TCGA_subtypes & Classical & 23 & 15 & 8 & 3.326 & 0.020 \\
\hline \multirow[t]{3}{*}{ PRS type } & Primary & 264 & 135 & 129 & 0.182 & 0.834 \\
\hline & Secondary & 11 & 4 & 7 & & \\
\hline & Recurrent & 23 & 13 & 10 & & \\
\hline
\end{tabular}

After $9 \mathrm{~h}$, cells in the upper chamber were erased and cells in the lower chamber were fixed by $4 \%$ paraformaldehyde followed by $0.1 \%$ crystal violet staining. The procedure for the invasion assay was similar to that for the migration assay, except that the transwell membranes were pre-coated with Matrigel (R\&D Systems, USA) and the cells were incubated for $18 \mathrm{~h}$ at $37^{\circ} \mathrm{C}$ in a $5 \% \mathrm{CO}_{2}$ atmosphere. The stained cells were examined in the microscope and counted by ImageJ.

\section{Soft agar colony formation assay}

$1.2 \%$ Agarose as the lower gel was prepared and 1:1 mixed with $2 \times$ DMEM complete medium followed by addition to 6-well plate. $2 \mathrm{ml} 2 \times$ DMEM containing $1 \times 10^{3}$ cells complete medium was 1:1 mixed with $0.6 \%$ Agarose which was the lower gel and quickly added to the culture plate after the solidification of lower gel. After the solidification of the upper gel, the 6-well plate was cultured in the incubator for 2-3 weeks. $0.1 \%$ crystal violet was used for staining and examined in the microscope. The colony was counted by ImageJ.

\section{Dual-luciferase reporter gene assay}

The CBL promoter was recombined into PGL3-basic plasmid and cotransfected with indicated plasmids and pGL3-TK plasmid into 293FT cells. The empty vector was considered as the negative control. After 2 days, cells were treated and analyzed by protocol from dual-luciferase reporter assay kit (Promega, USA).

\section{Gene set enrichment analysis (GSEA)}

To determine whether $\mathrm{ZC} 3 \mathrm{H} 15$ expression was correlated with the EGFR signaling pathway in GBM, GSEA (version 4.0.3) was used. The CGGA database was downloaded from the Chinese Glioma Genome Atlas (http:// www.cgga.org.cn/). The gene sets were obtained from the Molecular Signatures Database (MsigDB, http://software.broadinstitute.org/gsea/ index.jsp).

\section{Xenograft assay}

The procedure was performed as described previously [22]. Briefly, 4-weekold female NOD/SCID mice (Beijing Animal Research Center) were purchased and housed in the SPF room. $1 \times 10^{5}$ U-87 MG cells stably transfected with Scramble or shZC3H15 were intracranially injected slowly into the brain of each mouse. Mice were divided into two groups, one group ( 6 mice for each subgroup) was used for H\&E staining, the other group (6 mice for each subgroup) was monitored for survival. Isoflurane anesthesia was used to reduce the pain of the mice when the tumors were harvested. Randomization and single blinding were used for measurement, and the tumor volumes were measured using length (a) and width (b) and calculated using the equation: $V=a b^{2} / 2$. The data represent the means \pm SD. The bodies were stored at $-20^{\circ} \mathrm{C}$ and then incinerated by Laibite Biotech Inc. (Chongqing, China). All animal studies were approved by the Institutional Animal Care and Use Committee of Southwest University.

\section{Statistical process}

Triplicates were designed and performed in each experiment mentioned above. Statistical parameters including the sample size and the significance analysis are specified in figure legends. Data was analyzed and shown as mean \pm SD. Statistics were analyzed by GraphPad Prism 7.0 whereas the image was analyzed by ImageJ. The Two-tailed Student's $t$ test was used to analyze the data from two groups. The data was considered as significance if the $p$-value $<0.05,{ }^{*} P<0.05,{ }^{* *} P<0.01,{ }^{* * *} P<0.001$.

\section{RESULT}

ZC3H15 is commonly upregulated in GBM and correlates with poor prognosis

We downloaded the data from the CGGA database and ranked them by the WHO analysis method, the expression level of $\mathrm{ZC} 3 \mathrm{H} 15$ increased with the malignant degree of glioma (Fig. 1A). To further determine the role of $\mathrm{ZC} 3 \mathrm{H} 15$ in glioma, we analyzed the characteristics of glioma patients related to $\mathrm{ZC} 3 \mathrm{H} 15$ expression based on the CGGA database. As shown in Table 2, ZC3H15 expression was dramatically associated with grade and TCGA subtypes in glioma (Table 2). Isocitrate dehydrogenase (IDH) mutation is commonly observed in glioma, and they are proved to possess the ability to improve the survival rate. We observed that $\mathrm{ZC} 3 \mathrm{H} 15$ expression in the IDH mutation group was lower than in the wildtype group (Fig. S1A). Moreover, ZC3H15 expression was also correlated with patients' age (Fig. S1B). The older the patients, the higher the expression of $\mathrm{ZC} 3 \mathrm{H} 15$ in the tumor. We also analyzed the data obtained from the TCGA database, the expression of $\mathrm{ZC} 3 \mathrm{H} 15$ is the highest in GBM which is the top level of glioma (Fig. 1B). Furthermore, the clinical data from the TCGA database also indicated that gene copy number gain for $\mathrm{ZC} 3 \mathrm{H} 15$ was linked to high expression of $\mathrm{ZC} 3 \mathrm{H} 15$ in glioma 

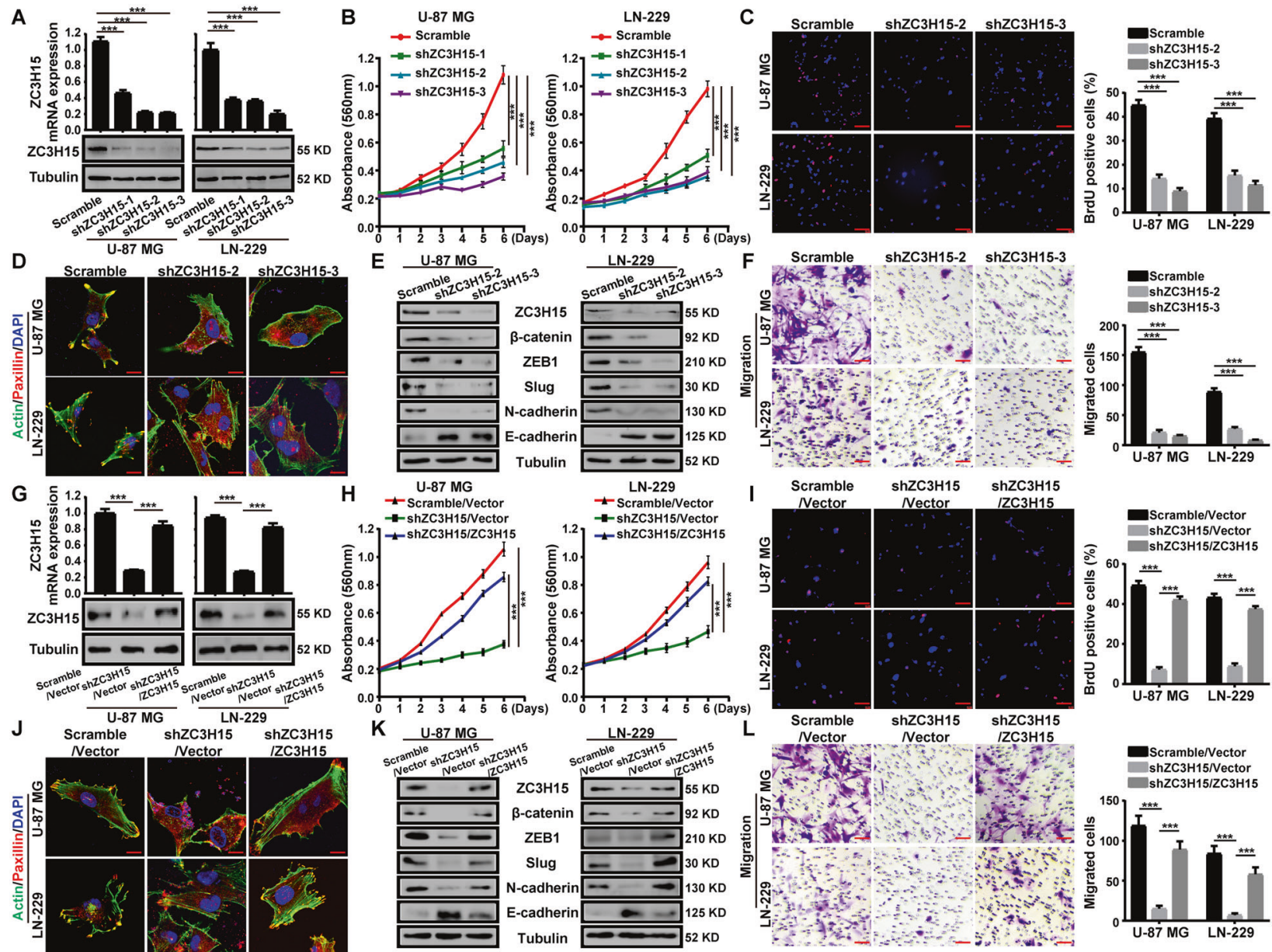

Fig. $2 \mathrm{ZC} 3 \mathrm{H} 15$ is essential for cell proliferation, migration and invasion of GBM cells. A Western Blot and qRT-PCR assay were performed to prove the knockdown of ZC3H15. B, C The cells viability and BrdU incorporation were detected by MTT and BrdU assay. BrdU positive cells were counted. D ZC3H15-knockdown and control cells were plated on glass slides and stained with anti-Paxillin and anti-actin antibodies. DAPI was used for nuclear staining. E The expressions of metastasis-associated proteins were evaluated through western blot analysis in ZC3H15-knockdown and control cells. Tubulin was used as a control for normalization. $\mathbf{F}$ The effect of ZC3H15 knockdown on cell migration was detected by transwell assay, the migrated cells were counted and analyzed. G Western blot and RT-PCR analysis were performed to detect the expression of $\mathrm{ZC} 3 \mathrm{H} 15$ in the indicated cells. $\mathbf{H}$, I The proliferation abilities of indicated cells were analyzed by MTT and BrdU assays. BrdU positive cells were counted and analyzed. $\boldsymbol{J}$ Indicated cells were plated on glass slides and stained with anti-Paxillin and anti-actin antibodies. DAPI was used for nuclear staining. K The expressions of metastasis-associated proteins were evaluated through western blot analysis in GBM cells. Tubulin was used as a control for normalization. L The migration ability of indicated cells was detected by transwell assay. All data were expressed as mean \pm SD. Student's $t$ test was performed to analyzed significance. ${ }^{*} P<0.05,{ }^{* *} P<0.01,{ }^{* * *} P<0.001$.

(Fig. 1C). These results suggested that $\mathrm{ZC} 3 \mathrm{H} 15$ played as an onco-protein. To further determine whether high expression of $\mathrm{ZC} 3 \mathrm{H} 15$ was linked to the prognosis of tumor patients, survival data from CGGA database was analyzed. As shown in Fig. 1D, high expression of $\mathrm{ZC} 3 \mathrm{H} 15$ indicated poor prognosis, same results were also obtained in Phillips and Tumor Glioma-kawaguchi-50 database (Fig. 1E, F). Moreover, IHC staining assays revealed that ZC3H15 expression in malignant gliomas was significantly higher than the adjacent/normal brain tissue, and increases along with malignant stages (Fig. 1G). After that, the protein and mRNA expression of $\mathrm{ZC} 3 \mathrm{H} 15$ were examined and demonstrated that higher mRNA level and protein level of $\mathrm{ZC} 3 \mathrm{H} 15$ were found in $\mathrm{LN}$ 229, A172, U-87 MG cells (Fig. 1H). Taken together, we demonstrated that $\mathrm{ZC} 3 \mathrm{H} 15$ was overexpressed in $\mathrm{GBM}$ and was associated with a poor prognosis of GBM patients.

\section{ZC3H15 is essential for cell proliferation, migration and invasion of GBM cells}

According to the expression profile we obtained before (Fig. $1 \mathrm{H})$, U-87 MG and LN-229 cells were utilized in this study. We knocked down the expression of $\mathrm{ZC} 3 \mathrm{H} 15$ with three shRNA sequences, shZC $3 \mathrm{H} 15$ no.1, 2, and 3. The shZC $3 \mathrm{H} 15-3$ sequence showed more efficiency and was used in the following experiments (Fig. 2A). $\mathrm{MTT}$ assays were performed and the data demonstrated that silencing of $\mathrm{ZC} 3 \mathrm{H} 15$ significantly inhibited cell proliferation of GBM cells (Fig. 2B). We further examined the bromodeoxyuridine (BrdU) incorporation, and the results indicated that $\mathrm{ZC} 3 \mathrm{H} 15$ knockdown significantly reduced DNA synthesis ability (Fig. 2C). Next, flow cytometry analysis was performed to detect the cell cycle and apoptosis in $\mathrm{ZC} 3 \mathrm{H} 15$ knockdown and control cells (Figs. $\mathrm{S} 2, \mathrm{~S} 3$ ). We found that silencing of $\mathrm{ZC} 3 \mathrm{H} 15$ induced the $\mathrm{G} 1$ arrest in GBM cells. However, we did not detect obvious cell apoptosis in the $\mathrm{ZC} 3 \mathrm{H} 15$ knockdown group. Moreover, cell senescence experiments were performed and showed that the number of senescent cells increased significantly after ZC3H15 knockdown (Fig. S4). Ectoderm cellular matrix (ECM) remodeling is the main mechanism for GBM invasion and is also the difficulty in curing recurrent brain cancer patients. Paxillin is a cytoskeletal protein involved in actin-membrane attachment to extracellular matrix cell adhesion (adhesion spot) sites [29]. We found that the paxillin 

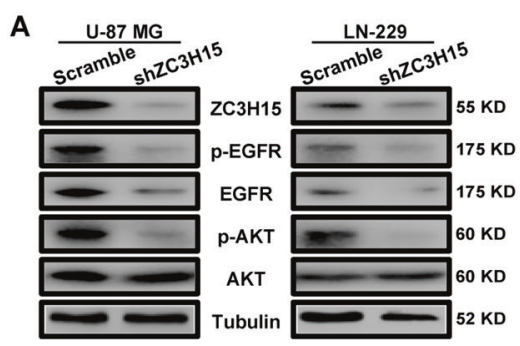

E
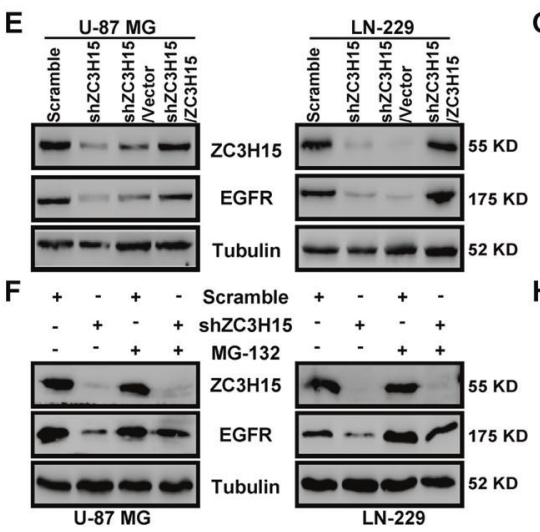
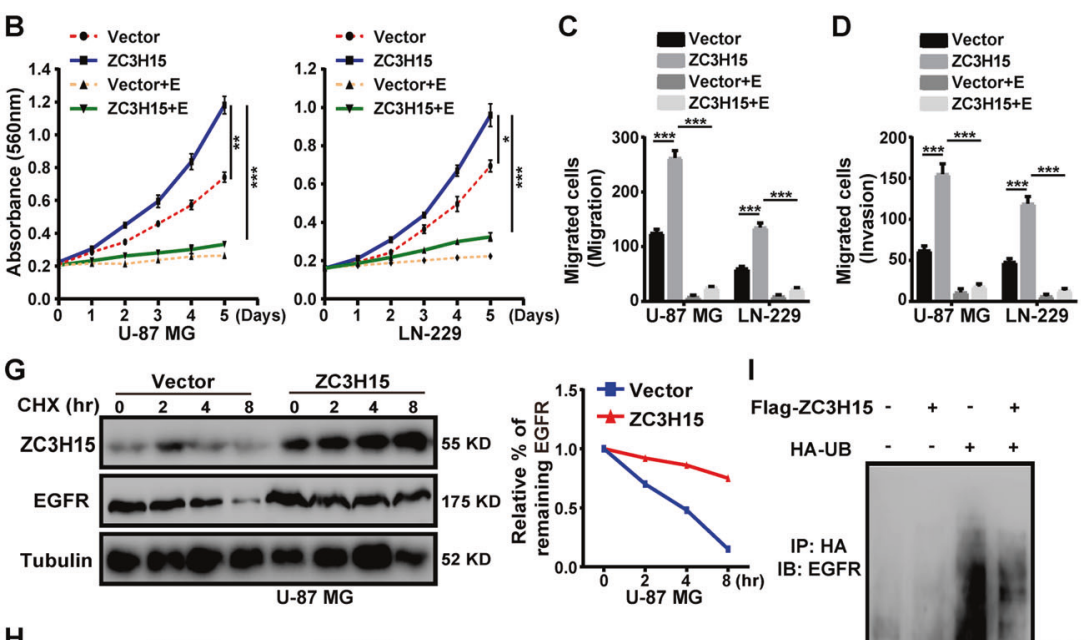

I

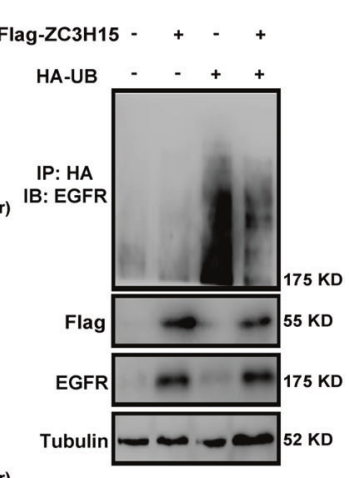

Fig. 3 ZC3H15 activates the EGFR-mediated signaling pathway by increasing EGFR protein stability. A Western blot analysis was performed to detect the expression of EGFR signaling proteins (EGFR, p-EGFR, AKT, p-AKT) of GBM cells. B The inhibitory effect of EGFR inhibitor-erlotinib on the proliferation activity in control or ZC3H15 overexpression cells. C, D The inhibitory effect of EGFR inhibitor-erlotinib on the invasion and migration in control and $\mathrm{ZC} 3 \mathrm{H} 15$ overexpression cells. The number of cells invaded and migrated were counted and analyzed. E Western blot analysis was performed to detect the protein expression of EGFR in the indicated cells. $\mathbf{F}$ Cells were treated with MG132 for $8 \mathrm{~h}$ before harvesting to detect the protein level of EGFR in the indicated cells. $\mathbf{G}, \mathbf{H ~ C H X}$ treatment for time gradient $(0 \mathrm{~h}, 2 \mathrm{~h}, 4 \mathrm{~h}, 8 \mathrm{~h})$ with the $\mathrm{ZC} 3 \mathrm{H} 15$ overexpression and control group. To determine whether ZC $3 \mathrm{H} 15$ could stabilize EGFR. The gray value was calculated by ImageJ. I HA-tagged Ub plasmid and Flag-tagged ZC3H15 plasmid were co-transfected into the cells. The ubiquitinated EGFR proteins were pulled down with anti-HA antibody and immunoblotted with ant-EGFR antibody. All data were expressed as mean \pm SD. Student's $t$ test was performed to analyzed significance. ${ }^{*} P<0.05,{ }^{* *} P<0.01,{ }^{* *} P<0.001$.

protein at the actin-membrane attachment site was dissipated after ZC3H15 knockdown (Fig. 2D). It suggested that ZC3H15 participated in the adhesion and metastasis of tumor cells. After that, we detected the variation of proteins related to cell adhesion. The results demonstrated that the protein levels of $\beta$-catenin, ZEB1, Slug, N-cadherin were decreased after ZC3H15 knockdown, while the protein expression of E-cadherin was increased (Fig. 2E). In addition, the abilities of migration and invasion were also reduced in $\mathrm{ZC} 3 \mathrm{H} 15$ knockdown GBM cells (Fig. $2 \mathrm{~F}$ and Fig. S5A).

To further investigate whether $\mathrm{ZC} 3 \mathrm{H} 15$ was essential for GBM cells, restoration assay was conducted. Both protein level and mRNA level of $\mathrm{ZC} 3 \mathrm{H} 15$ were recovered in $\mathrm{ZC} 3 \mathrm{H} 15$ knockdown GBM cells after treatment with $\mathrm{ZC} 3 \mathrm{H} 15$ overexpression (Fig. $2 \mathrm{G}$ ). The abilities of cell proliferation, migration, and invasion of $\mathrm{ZC} 3 \mathrm{H} 15$ knockdown cells were also restored in $\mathrm{ZC} 3 \mathrm{H} 15$ restored group compared to control cells (Fig. 2H, I, L and Fig. S5B). Meanwhile, the distribution of paxillin and the related protein levels were also restored (Fig. 2J, K). Therefore, these findings indicated that $\mathrm{ZC} 3 \mathrm{H} 15$ was involved in cell proliferation, migration, and invasion of GBM cells.

\section{ZC3H15 activates the EGFR-mediated signaling pathway by increasing EGFR protein stability}

The protein level of EGFR is highly upregulated in GBM cells, and numerous cellular processes are regulated by EGFR, including cell proliferation, migration, and invasion [30-32]. Interestingly, the GSEA analysis using the CGGA database indicated that high $\mathrm{ZC} 3 \mathrm{H} 15$ expression was positively associated with EGFR signaling genes in glioma (Fig. S6). To further validate the data, we next examined the expression and phosphorylation of EGFR and its downstream target protein AKT. The results showed that EGFR and AKT phosphorylation as well as the expression of EGFR were significantly reduced by $\mathrm{ZC} 3 \mathrm{H} 15$ knockdown (Fig. $3 \mathrm{~A}$ ). Erlotinib is a small molecular inhibitor that targeted EGFR activation [27, 33]. To determine whether the proliferative effect and the metastatic effect of $\mathrm{ZC} 3 \mathrm{H} 15$ on GBM cells were EGFR dependent, we treated ZC3H15-overexpression and control cells with erlotinib. MTT assays demonstrated that erlotinib clearly decreased the promotive effect of $\mathrm{ZC} 3 \mathrm{H} 15$ overexpression on cell proliferation (Fig. 3B). Besides, the migration and invasion abilities of GBM cells were also inhibited after treatment with erlotinib (Fig. 3C, D and Fig. S7). Thus, these results demonstrated that $\mathrm{ZC} 3 \mathrm{H} 15$ promoted cell proliferation, migration, and invasion by activating EGFR signaling pathway.

We have already shown that the protein level of EGFR was decreased in $\mathrm{ZC} 3 \mathrm{H} 15$ knockdown cells, in accordance with expectations, the protein level of EGFR was recovered in ZC3H15-overexpression ZC3H15 knockdown cells (Fig. 3E). In addition, we also detected the mRNA expression of EGFR and found that the mRNA expression of EGFR remained constant (Fig. S8). It has been reported that EGFR may be degraded by the ubiquitin-proteasomal system [34, 35]. Hence, we treated $\mathrm{ZC} 3 \mathrm{H} 15$ knockdown cells with the proteasomal inhibitor MG132. The protein level of EGFR was rescued by treatment with MG-132

(Fig. 3F). Moreover, ZC3H15 overexpression could effectively stabilize EGFR protein from degradation when treating cells with de novo protein synthesis inhibitor cycloheximide (CHX) (Fig. 3G, H). To further verify the stabilization ability of ZC3H15 to EGFR, we detected the ubiquitination level of EGFR. ZC3H15 overexpression significantly reduced EGFR ubiquitination (Fig. 

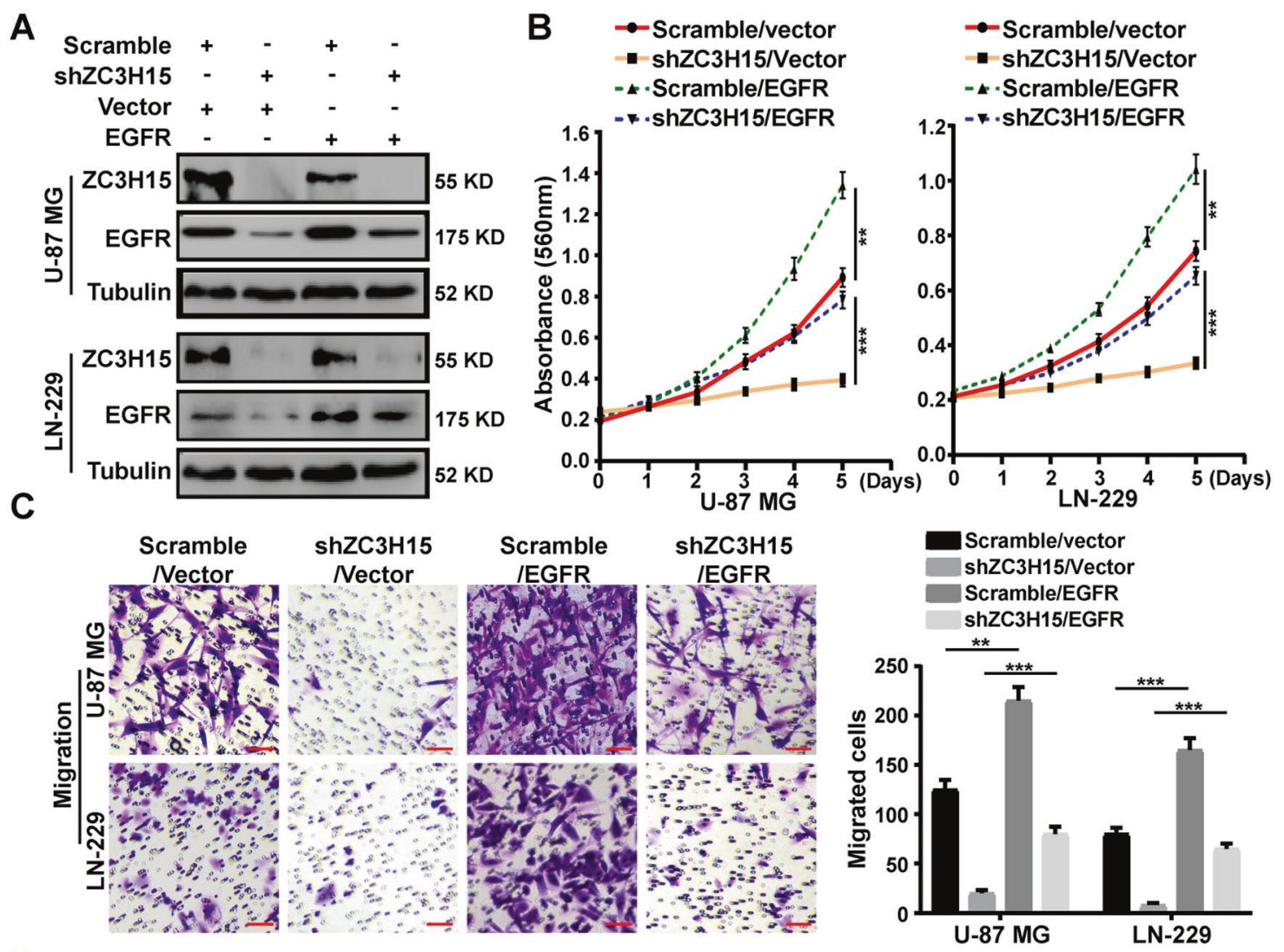

D
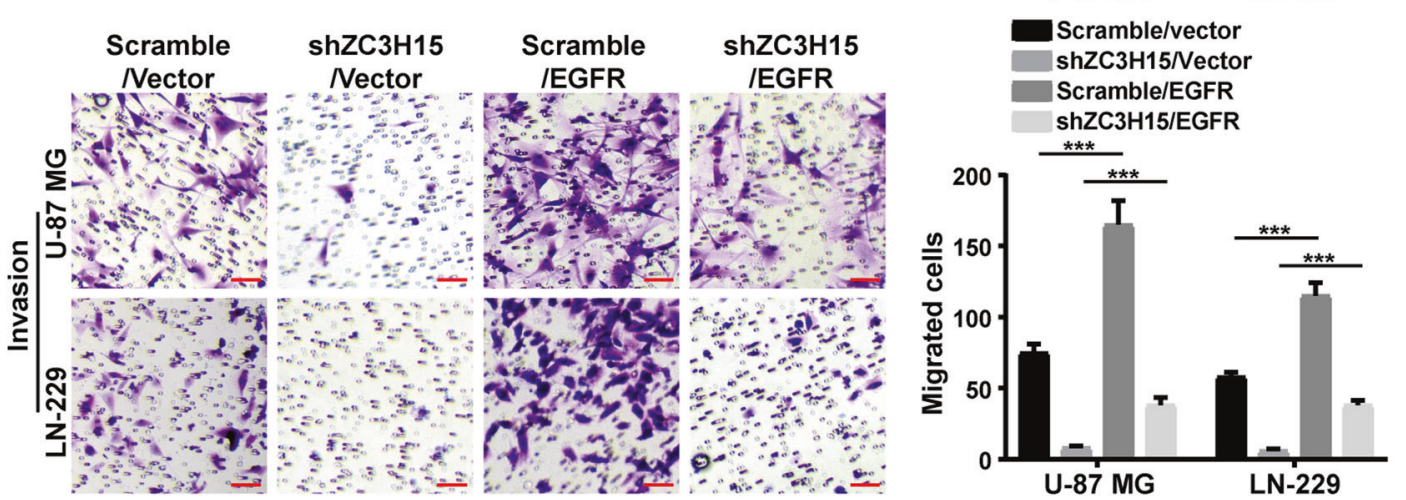

Fig. 4 EGFR overexpression significantly restored cell proliferation, migration, and invasion of ZC3H15-knockdown GBM cells. A The protein level of ZC3H15 and EGFR were detected in the indicated GBM cells. B MTT assays were performed to examine the effect of EGFR overexpression on the cell proliferation of ZC3H15-knockdown GBM cells. C, D Transwell assays were used to detect the effects of EGFR overexpression on cell migration and invasion of $\mathrm{ZC} 3 \mathrm{H} 15-\mathrm{knockdown}$ GBM cells. All data were expressed as mean $\pm \mathrm{SD}$. Student's $t$ test was performed to analyzed significance. ${ }^{*} P<0.05,{ }^{* *} P<0.01,{ }^{* *} P<0.001$.

3I). Therefore, these results revealed the role of $\mathrm{ZC} 3 \mathrm{H} 15$ in activating the EGFR signaling pathway is to reduce the ubiquitination degradation of EGFR.

EGFR overexpression significantly restored cell proliferation, migration, and invasion of ZC3H15-knockdown GBM cells

To confirm whether $\mathrm{ZC} 3 \mathrm{H} 15$ regulated GBM progression by targeting EGFR degradation, we overexpressed EGFR in ZC3H15-knockdown U87 MG and LN-229 cells (Fig. 4A). MTT assays were performed and demonstrated that the inhibition effects of $\mathrm{ZC} 3 \mathrm{H} 15$ knockdown on cell proliferation were significantly restored after EGFR overexpression treatment (Fig. 4B). In addition, transwell assays were also performed and indicated that EGFR overexpression dramatically elevated the abilities of migration and invasion of $\mathrm{ZC} 3 \mathrm{H} 15$-knockdown GBM cells (Fig. 4C, D). Therefore, these data indicated that $\mathrm{ZC} 3 \mathrm{H} 15$ promoted GBM progression by increasing EGFR expression.

\section{ZC3H15 suppressed the transcription of E3 ligase CBL}

It has been reported that EGFR can be ubiquitinated for degradation by several E3 ubiquitin ligases, including CBL, STUB1, PARK2 $[22,36,37]$. Meanwhile, $\mathrm{ZC} 3 \mathrm{H} 15$ possesses the ability of transcription regulation [5]. We hypothesis that $\mathrm{ZC} 3 \mathrm{H} 15$ may regulate the transcription of some E3 ubiquitin ligases. Hence, we detected the expression of E3 ubiquitin ligases mentioned above in $\mathrm{ZC} 3 \mathrm{H} 15$ knockdown cells. Unsurprisingly, the protein level of $\mathrm{CBL}$ increased significantly while other E3s remained the same (Fig. 5A). To further verify that $\mathrm{ZC} 3 \mathrm{H} 15$ knockdown increases $\mathrm{CBL}$ expression through transcriptional regulation, qRT-PCR assay was performed. The mRNA level of $\mathrm{CBL}$ increased in $\mathrm{ZC} 3 \mathrm{H} 15-$ knockdown cells, which indicated that $\mathrm{ZC} 3 \mathrm{H} 15$ inhibited $\mathrm{CBL}$ transcription (Fig. 5B). The dual-luciferase reporter assay also proved it, increased luciferase activity was observed in $\mathrm{ZC} 3 \mathrm{H} 15-$ downregulation cells, while the luciferase activity was reduced in 
A

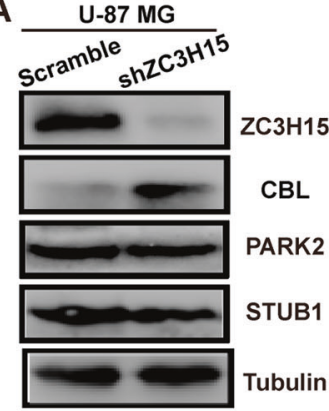

C

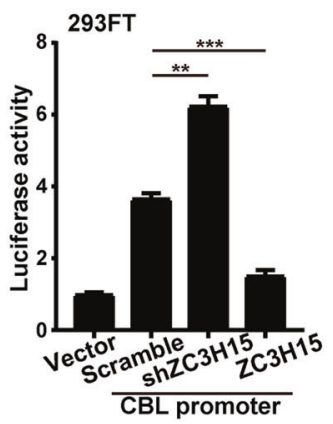

F

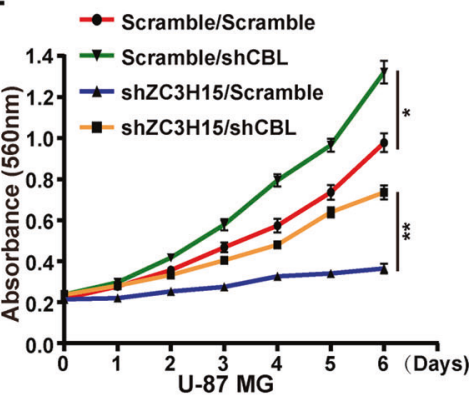

G

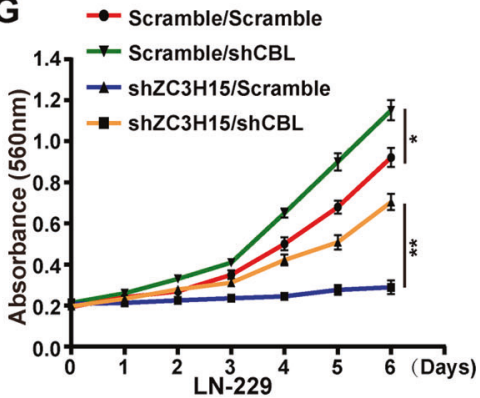

B

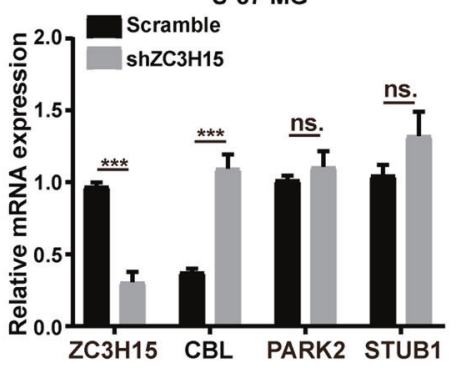

LN-229

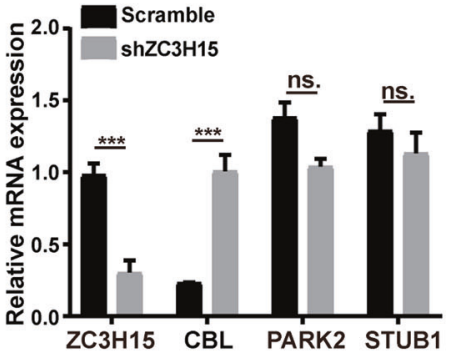

E

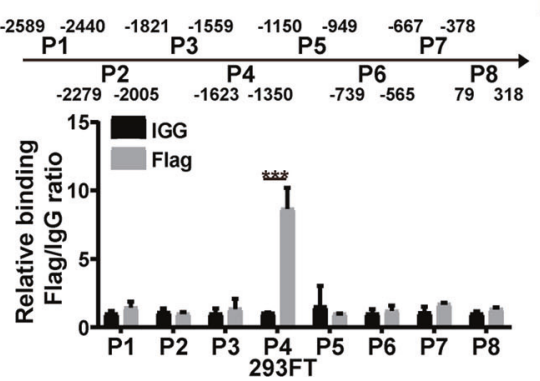

U-87 MG
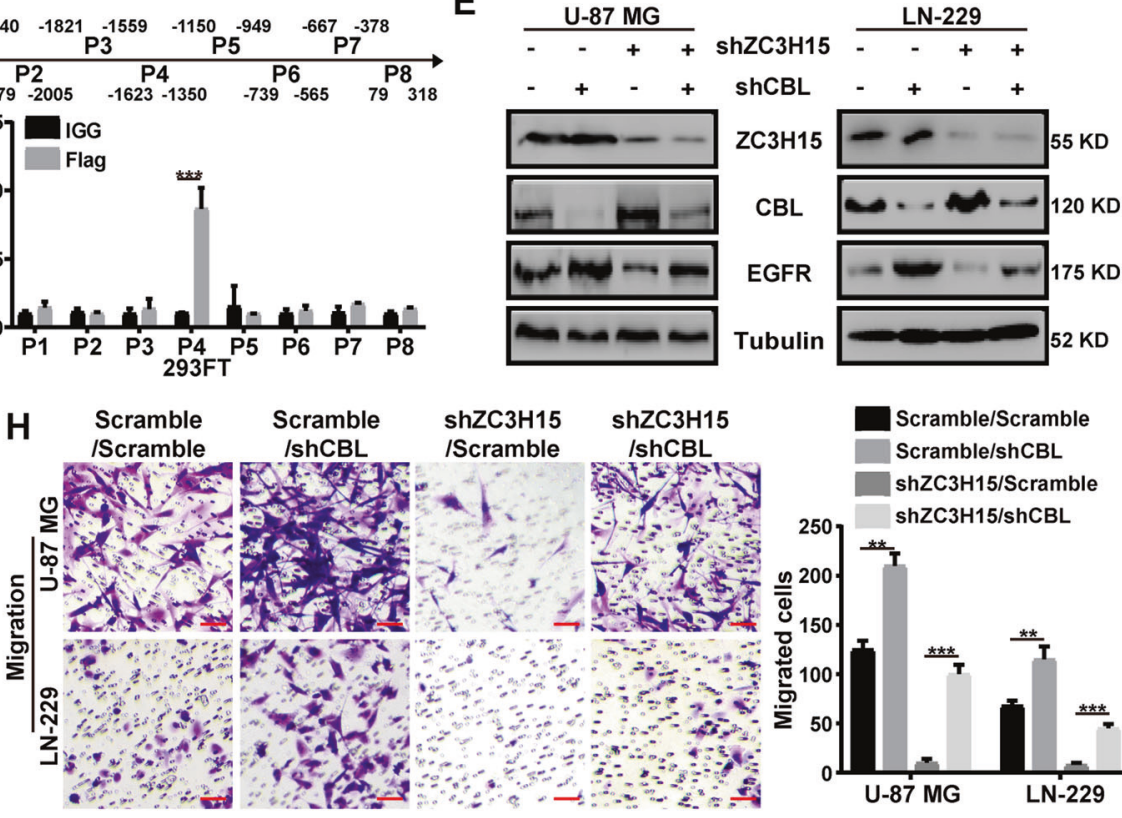

shZC $3 \mathrm{H} 15$

Scramble IshCBL

Scramble/Scramble

Scramble/shCBL

shZC3H15/Scramble

shZC3H15/shCBL
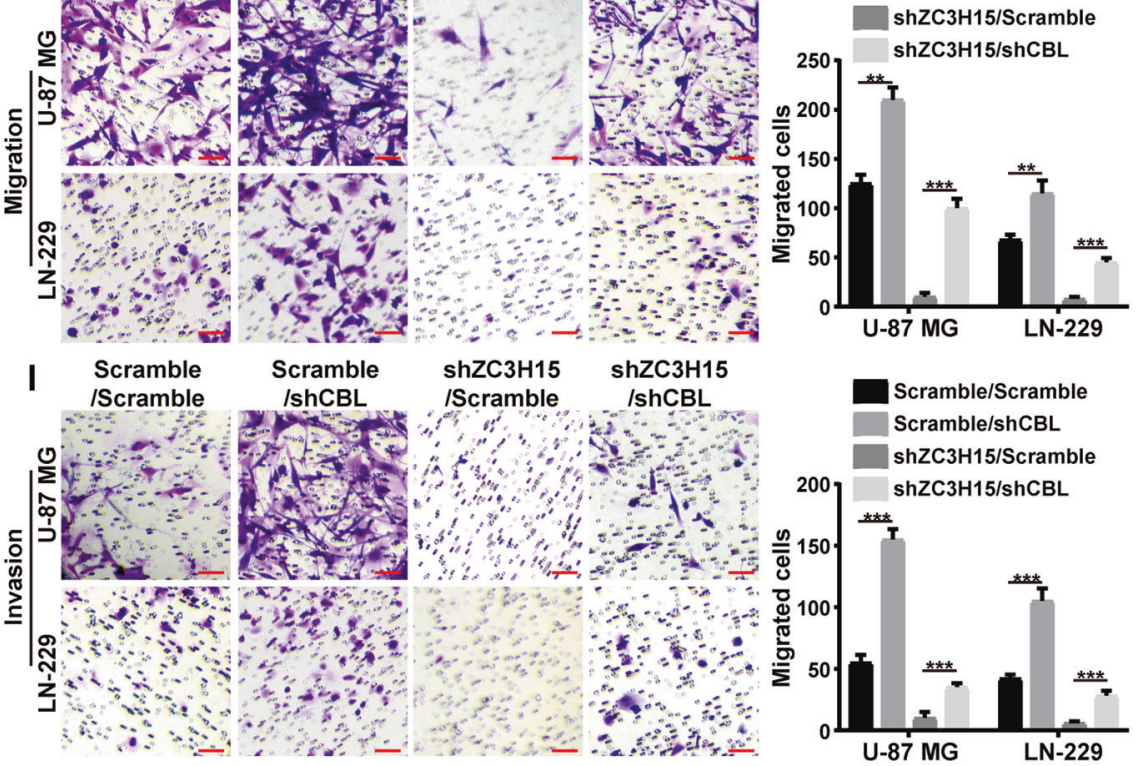

shZC3H15 shZC3H15

IScramble

IshCBL
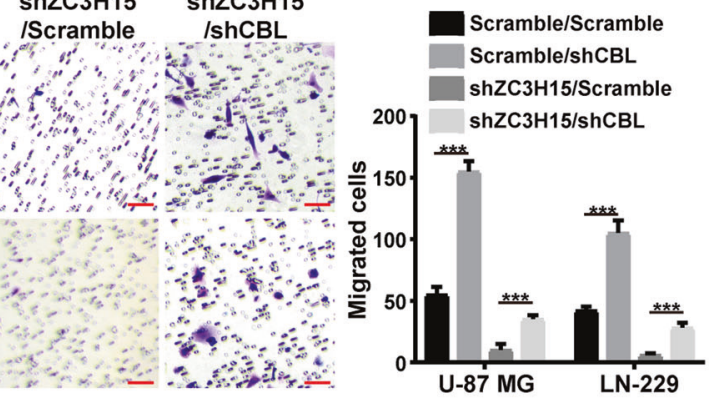

Fig. $5 \mathrm{ZC} 3 \mathrm{H} 15$ suppressed the transcription of E3 ligase CBL. A, B The protein level and mRNA level of several E3 ubiquitin ligases were detected in $\mathrm{ZC} 3 \mathrm{H} 15$ knockdown and control cells. C The transcriptional activity of CBL in control and ZC3H15 knockdown and overexpression group were detected. D ChIP assay was performed by using Flag antibodies. IgG was used as the negative control. E The protein levels of ZC3H15, CBL, and EGFR were detected by western blot analysis. F, G The recovery of cellular proliferation was detected in ZC3H15-knockdown cells followed by CBL knockdown. $\mathbf{H}$, I The recovery of the migration and invasion abilities in ZC3H15-knockdown cells followed by CBL knockdown. All data were expressed as mean \pm SD. Student's $t$ test was performed to analyzed significance. ${ }^{*} P<0.05,{ }^{* *} P<0.01,{ }^{* * *} P<0.001$.

ZC3H15-overexpression cells (Fig. 5C). Then, we detected the position of $\mathrm{ZC} 3 \mathrm{H} 15$ binding $\mathrm{CBL}$ promoter through the ChIP assays, and the results demonstrated that $\mathrm{ZC} 3 \mathrm{H} 15$ was enriched at the P4 fragment (Fig. 5D). Our previous data revealed that $\mathrm{ZC} 3 \mathrm{H} 15$ decreased CBL level and increased EGFR level (Figs. 3A, 5A). To further verify that $\mathrm{ZC} 3 \mathrm{H} 15$ stabilized EGFR through transcription inhibition of $\mathrm{CBL}$, we knocked down $\mathrm{CBL}$ expression in $\mathrm{ZC} 3 \mathrm{H} 15-$ downregulation GBM cells. We designed three CBL-knockdown plasmids, and shCBL-3 showed more efficient and was used in the following experiments (Fig. S9). Then, western blot experiments were performed and demonstrated that the EGFR protein level was dramatically increased after CBL-downregulation treatment
(Fig. 5E). Consistently, the abilities of cell proliferation, migration, and invasion of ZC3H15-knockdown cells were significantly increased after CBL-knockdown treatment (Fig. 5F-I). In general, these findings indicated that $\mathrm{ZC} 3 \mathrm{H} 15$ inhibited $\mathrm{CBL}$ transcription to further stabilize EGFR and promote cell proliferation, migration, and invasion.

\section{ZC3H15 knockdown inhibits tumor growth and improved prognosis in mice}

To investigate the colony formation effects of ZC3H15 in GBM, soft agar assays were performed and demonstrated that the knockdown group exhibited fewer and smaller colonies (Fig. 6A). To 
A
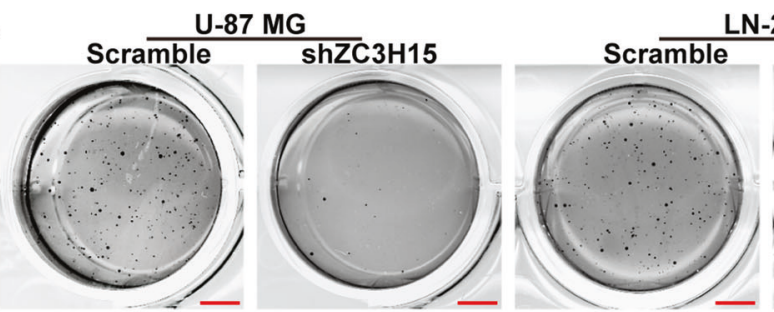
shZC $3 \mathrm{H} 15$
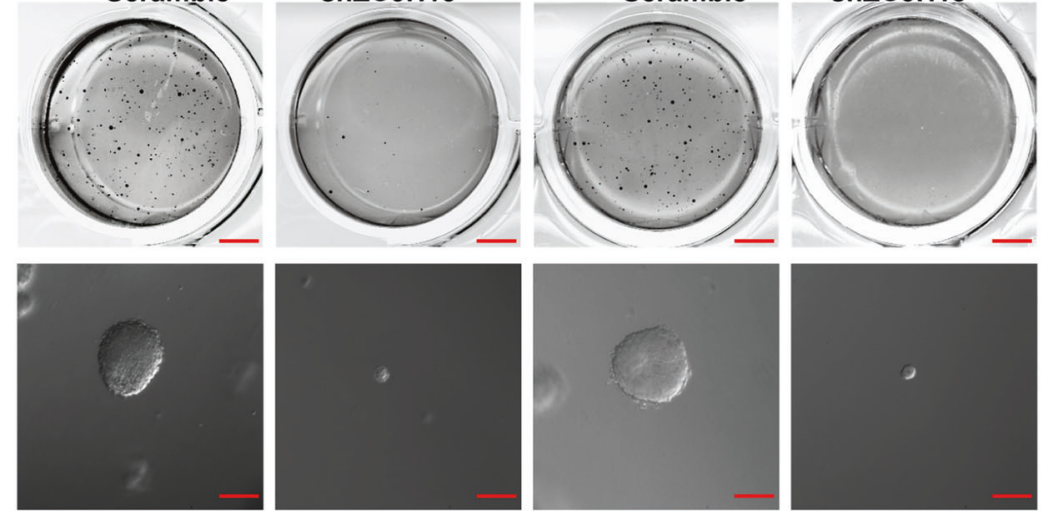

B
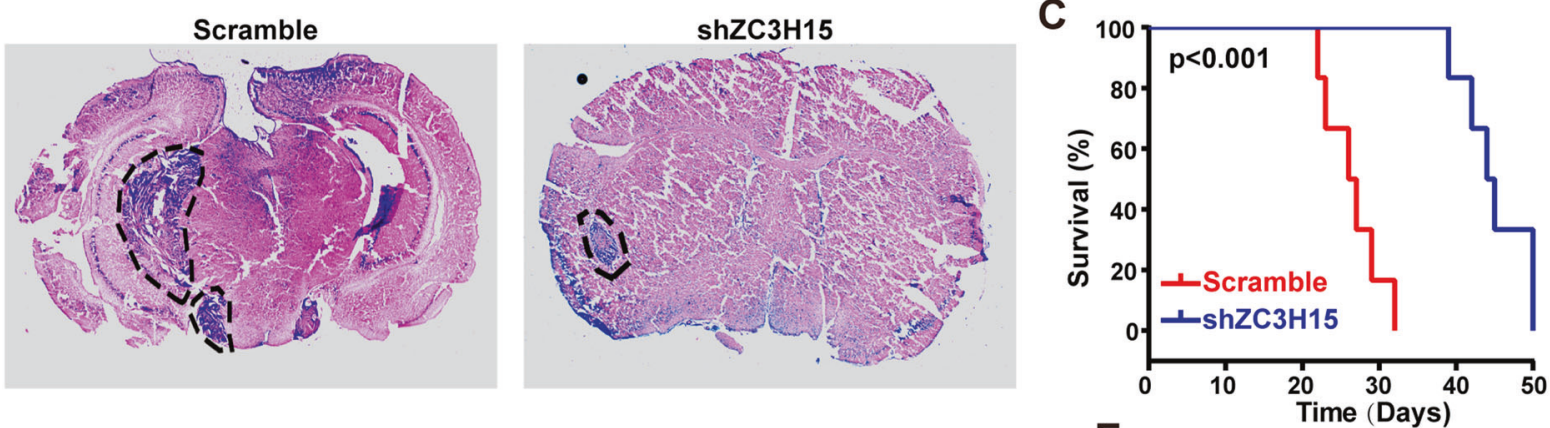

D
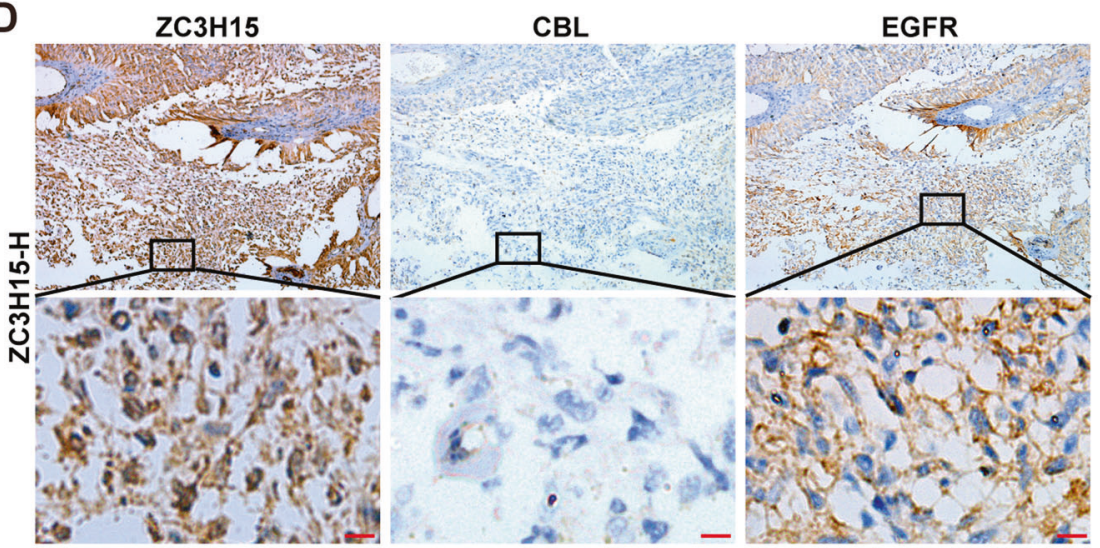

$\mathbf{E}$
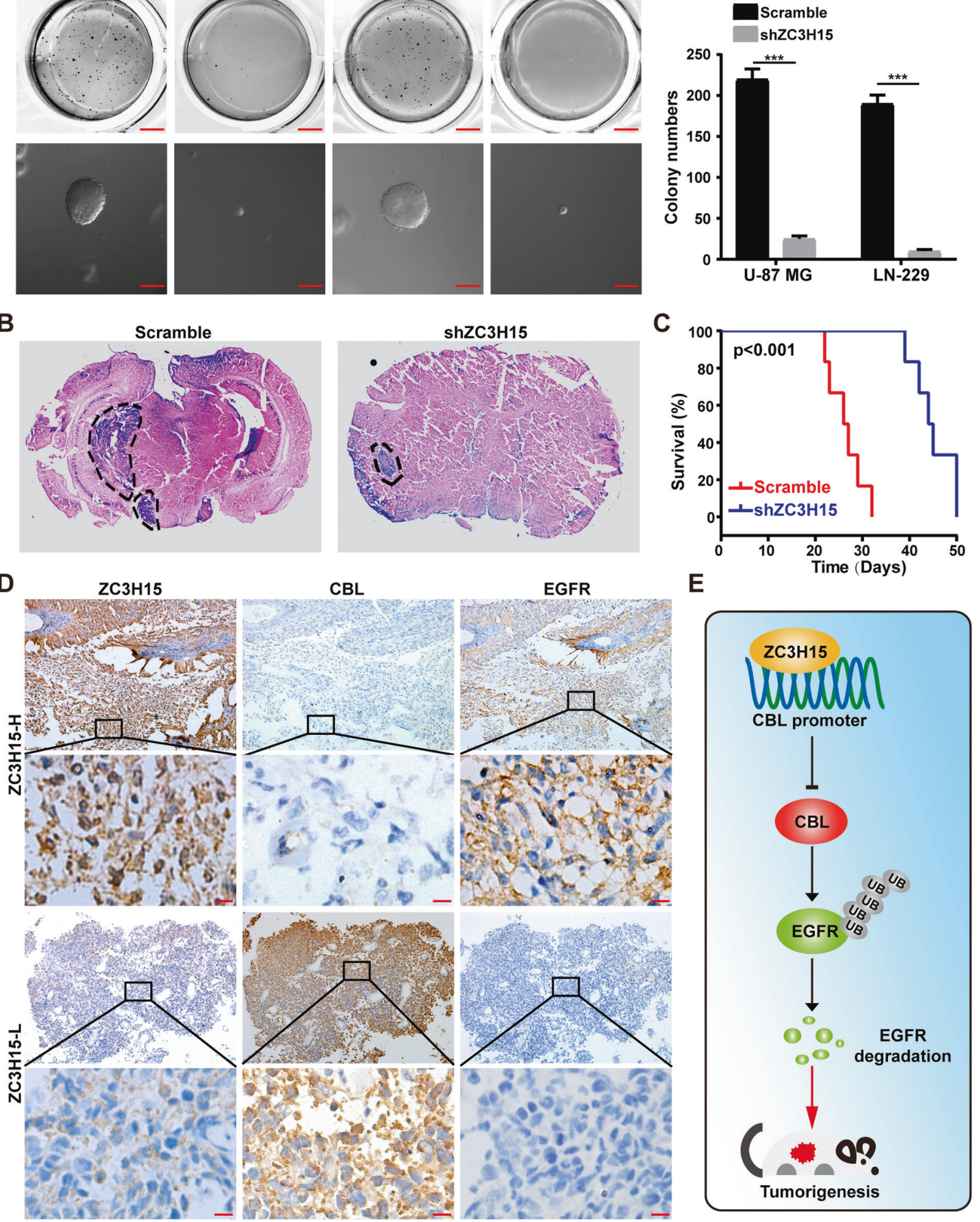

Fig. 6 ZC3H15 knockdown inhibits tumor growth and improved prognosis in mice. A The colony formation ability of GBM cells was detected by soft agar assay. B Orthotopic implantation experiment was performed to assess the in vivo tumor formation capabilities of ZC3H15-knockdown and control cells. C The survival curve of mice was plotted based on the living days of mice after the in-situ injection. D The expression levels of ZC3H15, CBL, and EGFR were stained and showed in the representative section of tumor samples of GBM patients. $\mathrm{ZC} 3 \mathrm{H} 15-\mathrm{H}, \mathrm{ZC} 3 \mathrm{H} 15$ high expression; ZC3H15-L: ZC3H15 low expression. E Model of the impact of the ZC $3 \mathrm{H} 15$ on regulating cell proliferation, migration, invasion, and tumorigenesis of GBM cells. The data were expressed as mean \pm SD. Student's $t$ test was performed to analyzed significance. ${ }^{*} P<0.05,{ }^{* *} P<0.01,{ }^{* * *} P<0.001$. 
further determine the functional role of $\mathrm{ZC} 3 \mathrm{H} 15$ in the tumor growth of GBM cells, the intracranial injection assay was performed. The results showed that $\mathrm{ZC} 3 \mathrm{H} 15$ downregulation significantly retarded the tumor formation capabilities of GBM cells (Fig. 6B). Moreover, mice in the $\mathrm{ZC} 3 \mathrm{H} 15$-knockdown group survived significantly longer than those in the control group (Fig. 6C). Next, in patient samples, the expression of EGFR was positively correlated to $\mathrm{ZC} 3 \mathrm{H} 15$, whereas, $\mathrm{CBL}$ was negatively correlated to ZC3H15 and EGFR (Fig. 6D). These results indicated that $\mathrm{ZC} 3 \mathrm{H} 15$ promoted tumor growth of GBM cells by targeting the CBL/EGFR signaling pathway (Fig. $6 \mathrm{E}$ ).

\section{DISCUSSION}

The chemotherapy and radiotherapy have little effects on GBM and surgical removal of the tumor cannot prevent the recurrence $[38,39]$. $\mathrm{ZC} 3 \mathrm{H} 15$ possesses the ability to promote cell proliferation, migration, invasion, and tumorigenesis. This indicates that overexpression of $\mathrm{ZC} 3 \mathrm{H} 15$ in GBM may invade and migrate further in resistance to chemotherapy or radiotherapy. Our previous analysis of $\mathrm{ZC} 3 \mathrm{H} 15$ overexpression reduced the survival rate is probably, at least in part proved this. Soft agar can simulate the growth environment in vivo. We found that $\mathrm{ZC} 3 \mathrm{H} 15$ downregulation reduced the growth and the colony number of GBM cells, which supports the role of $\mathrm{ZC} 3 \mathrm{H} 15$ in tumorigenesis.

EGFR is frequently upregulated in various cancers, including GBM [31]. Betacellulin (BTC) EGF and TGF etc. can bind with EGFR and activate downstream pathway [30]. We have shown that cells with high EGFR expression level were correlated with high proliferation ability [22]. Interestingly, ZC3H15 positively regulated the protein ability of EGFR. Given that EGFR can be ubiquitinated by E3 ligases, meanwhile, we found that the ubiquitination level of EGFR was reduced in the existence of $\mathrm{ZC} 3 \mathrm{H} 15[40,41]$. It is noteworthy that, $\mathrm{ZC} 3 \mathrm{H} 15$ has no Ring finger domain or HECT domain, which is crucial for targeting protein degradation [42]. So, we hypothesis that there is an E3 ubiquitin ligase regulated by $\mathrm{ZC} 3 \mathrm{H} 15$ and targeted EGFR for its degradation. Our data added a new pathway for $\mathrm{ZC} 3 \mathrm{H} 15$ promoting tumorigenesis which was poorly studied. In addition, small molecular inhibitors of EGFR have been developed, such as erlotinib and gefitinib. These drugs can inhibit the activation of EGFR [43]. However, due to the T790M mutation of EGFR, secondary resistance to these drugs will occur in a year. The future treatment tendency will be genes and drugs combination which is still warranted further study.

Casitas B-lineage (CBL), an E3 ligase which has been studied to involve numerous cellular functions, including immune regulation, proliferation, metastasis, and tumor suppressor $[12,44,45]$. However, disputes existed in the role of CBL played in the tumor, research showed that in non-small cell lung cancer, CBL downregulated PD-L1. So that the tumor can't confuse T cells. CBL possesses a critical role in the regulation of CD8 (+) T cells and CAR T-cell functions to increase immunity against the tumor. Moreover, $\mathrm{CBL}$ is also reported as a tumor suppressor gene in gastric cancer $[12,14,15,45]$. The detailed mechanisms of $C B L$ in immune regulation remain unclear $[12,45]$. Interestingly, $\mathrm{ZC} 3 \mathrm{H} 15$ is able to decrease the mRNA and protein level of $\mathrm{CBL}$ through transcriptional regulation, thereby promoting tumor growth. It is similar to the way $\mathrm{ZC} 3 \mathrm{H} 15$ regulates NF-KB signaling [5].

Our results in animal experiments and tumor samples showed that the promotion effect of the ZC3H15-CBL-EGFR axis to the tumor could be reappeared in vivo. Our Kaplan-Meier analysis from different database is the same as we obtained from mice, which is higher $\mathrm{ZC} 3 \mathrm{H} 15$ expression correlates with worse survival time.
In conclusion, we illustrated the role of $\mathrm{ZC} 3 \mathrm{H} 15$ as a transcription factor that stabilized the EGFR protein level via inhibiting CBL transcription to promote cancer progression. By regulating this axis, $\mathrm{ZC} 3 \mathrm{H} 15$ governed the axis, which was critical in tumorigenesis. Taken together, $\mathrm{ZC} 3 \mathrm{H} 15$ was an oncogene acting in tumor cells and with its great functional ability to control numerous cellular progressions. Our study of the $\mathrm{ZC} 3 \mathrm{H} 15-\mathrm{CBL}$ pathway on EGFR expression provided a brand-new insight into tumorigenesis. And these proteins we proposed can be the marker for anti-cancer drugs and combination treatment development.

\section{DATA AVAILABILITY}

All of the data and material in this paper are available when requested.

\section{REFERENCES}

1. Stupp R, Brada M, van den Bent MJ, Tonn JC, Pentheroudakis G. High-grade glioma: ESMO Clinical Practice Guidelines for diagnosis, treatment and follow-up. Ann Oncol. 2014;25:iii93-101.

2. Stupp R, Tonn JC, Brada M, Pentheroudakis G. High-grade malignant glioma: ESMO Clinical Practice Guidelines for diagnosis, treatment and follow-up. Ann Oncol. 2010;21:v190-3.

3. Claes A, Idema AJ, Wesseling P. Diffuse glioma growth: a guerilla war. Acta Neuropathol. 2007;114:443-58.

4. Luo JW, Wang X, Yang Y, Mao Q. Role of micro-RNA (miRNA) in pathogenesis of glioblastoma. Eur Rev Med Pharm Sci. 2015;19:1630-9.

5. Jiang BG, Wan ZH, Huang J, Li LM, Liu H, Fu SY, et al. Elevated ZC3H15 increases HCC growth and predicts poor survival after surgical resection. Oncotarget. 2016;7:37238-49.

6. Gregory RC, Lord KA, Panek LB, Gaines P, Dillon SB, Wojchowski DM. Subtraction cloning and initial characterization of novel epo-immediate response genes. Cytokine. 2000;12:845-57.

7. Ishikawa K, Azuma S, Ikawa S, Semba K, Inoue J. Identification of DRG family regulatory proteins (DFRPs): specific regulation of DRG1 and DRG2. Genes Cells. 2005;10:139-50.

8. Capalbo G, Mueller-Kuller T, Koschmieder S, Klein HU, Ottmann OG, Hoelzer D, et al. Characterization of $\mathrm{ZC} 3 \mathrm{H} 15$ as a potential TRAF-2-interacting protein implicated in the NFkappaB pathway and overexpressed in AML. Int J Oncol. 2013;43:246-54.

9. Fleischer TC, Weaver CM, MCAfee KJ, Jennings JL, Link AJ. Systematic identification and functional screens of uncharacterized proteins associated with eukaryotic ribosomal complexes. Genes Dev. 2006;20:1294-307.

10. Wout PK, Sattlegger E, Sullivan SM, Maddock JR. Saccharomyces cerevisiae Rbg1 protein and its binding partner Gir2 interact on Polyribosomes with Gen1. Eukaryot Cell. 2009;8:1061-71.

11. Venuprasad K. Cbl-b and itch: key regulators of peripheral T-cell tolerance. Cancer Res. 2010;70:3009-12.

12. Wang S, Xu L, Che X, Li C, Hou K, Fan Y, et al. E3 ubiquitin ligases Cbl-b and C-Cbl downregulate PD-L1 in EGFR wild-type non-small cell lung cancer. FEBS Lett. 2018;592:621-30.

13. Lemmon MA, Schlessinger J. Cell signaling by receptor tyrosine kinases. Cell. 2010;141:1117-34.

14. Dong Q, Ma Y, Zhang Y, Qu X, Li Z, Qi Y, et al. Cbl-b predicts postoperative survival in patients with resectable pancreatic ductal adenocarcinoma. Oncotarget. 2017;8:57163-73.

15. Xu L, Zhang Y, Qu X, Che X, Guo T, Cai Y, et al. E3 ubiquitin ligase Cbl-b prevents tumor metastasis by maintaining the epithelial phenotype in multiple drugresistant gastric and breast cancer cells. Neoplasia. 2017;19:374-82.

16. Normanno N, De Luca A, Bianco C, Strizzi L, Mancino M, Maiello MR, et al. Epidermal growth factor receptor (EGFR) signaling in cancer. Gene. 2006;366:2-16.

17. Yarden Y, Shilo BZ. SnapShot: EGFR signaling pathway. Cell. 2007;131:1018.

18. Kang ES, Oh MA, Lee SA, Kim TY, Kim SH, Gotoh N, et al. EGFR phosphorylationdependent formation of cell-cell contacts by Ras/Erks cascade inhibition. Biochim Biophys Acta. 2007;1773:833-43.

19. Miyamoto $\mathrm{Y}$, Suyama K, Baba H. Recent advances in targeting the EGFR signaling pathway for the treatment of metastatic colorectal cancer. Int J Mol Sci. 2017;18:752.

20. Reinehr R, Haussinger D. CD95 death receptor and epidermal growth factor receptor (EGFR) in liver cell apoptosis and regeneration. Arch Biochem Biophys. 2012;518:2-7. 
21. Wang P, Zhao L, Gong S, Xiong S, Wang J, Zou D, et al. HIF1alpha/HIF2alpha-Sox2/ KIf4 promotes the malignant progression of glioblastoma via the EGFR-PI3K/AKT signalling pathway with positive feedback under hypoxia. Cell Death Dis. 2021;12:312.

22. Hou J, Deng Q, Zhou J, Zou J, Zhang Y, Tan P, et al. CSN6 controls the proliferation and metastasis of glioblastoma by CHIP-mediated degradation of EGFR. Oncogene. 2017;36:1134-44.

23. Yarden Y, Sliwkowski MX. Untangling the ErbB signalling network. Nat Rev Mol Cell Biol. 2001;2:127-37.

24. Bublil EM, Yarden Y. The EGF receptor family: spearheading a merger of signaling and therapeutics. Curr Opin Cell Biol. 2007;19:124-34.

25. Li KS, Zhu XD, Liu HD, Zhang SZ, Li XL, Xiao N, et al. NT5DC2 promotes tumor cell proliferation by stabilizing EGFR in hepatocellular carcinoma. Cell Death Dis. 2020;11:335.

26. Minna JD, Dowell J. Erlotinib hydrochloride. Nat Rev Drug Discov. 2005;Suppl:S14-5.

27. Yang Z, Hackshaw A, Feng Q, Fu X, Zhang Y, Mao C, et al. Comparison of gefitinib, erlotinib and afatinib in non-small cell lung cancer: a meta-analysis. Int J Cancer. 2017;140:2805-19.

28. Bareschino MA, Schettino C, Troiani T, Martinelli E, Morgillo F, Ciardiello F. Erlotinib in cancer treatment. Ann Oncol. 2007;18:vi35-41.

29. Vollmann-Zwerenz A, Leidgens V, Feliciello G, Klein CA, Hau P. Tumor cell invasion in glioblastoma. Int J Mol Sci. 2020;21:1932.

30. An Z, Aksoy O, Zheng T, Fan QW, Weiss WA. Epidermal growth factor receptor and EGFRvIlI in glioblastoma: signaling pathways and targeted therapies. Oncogene. 2018;37:1561-75.

31. Eskilsson E, Rosland GV, Solecki G, Wang Q, Harter PN, Graziani G, et al. EGFR heterogeneity and implications for therapeutic intervention in glioblastoma. Neuro Oncol. 2018;20:743-52.

32. Fang R, Chen X, Zhang S, Shi H, Ye Y, Zou Z, et al. EGFR/SRC/ERK-stabilized YTHDF2 promotes cholesterol dysregulation and invasive growth of glioblastoma. Nat Commun. 2021;12:177.

33. Tagliamento M, Genova C, Rijavec E, Rossi G, Biello F, Dal MG. Bello, et al. Afatinib and Erlotinib in the treatment of squamous-cell lung cancer. Expert Opin Pharmacother. 2018;19:2055-62.

34. Shao G, Wang R, Sun A, Wei J, Peng K, Dai Q, et al. The E3 ubiquitin ligase NEDD4 mediates cell migration signaling of EGFR in lung cancer cells. Mol Cancer. 2018;17:24.

35. Yu JJ, Zhou DD, Yang XX, Cui B, Tan FW, Wang J, et al. TRIB3-EGFR interaction promotes lung cancer progression and defines a therapeutic target. Nat Commun. 2020;11:3660.

36. Deng M, Liu B, Song H, Yu R, Zou D, Chen Y, et al. beta-Elemene inhibits the metastasis of multidrug-resistant gastric cancer cells through miR-1323/Cbl-b/ EGFR pathway. Phytomedicine. 2020;69:153184.

37. Duan $\mathrm{H}$, Lei $Z$, Xu F, Pan $T$, Lu D, Ding $P$, et al. PARK2 suppresses proliferation and tumorigenicity in non-small cell lung cancer. Front Oncol. 2019;9:790.

38. Vasilev A, Sofi R, Rahman R, Smith SJ, Teschemacher AG, Kasparov S. Using light for therapy of glioblastoma multiforme (GBM). Brain Sci. 2020;10:E75.

39. Aldape K, Zadeh G, Mansouri S, Reifenberger G, von Deimling A. Glioblastoma: pathology, molecular mechanisms and markers. Acta Neuropathol. 2015;129:829-48.

40. Zhu Q, Dong H, Bukhari AA, Zhao A, Li M, Sun Y, et al. HUWE1 promotes EGFR ubiquitination and degradation to protect against renal tubulointerstitial fibrosis. FASEB J. 2020;34:4591-601.

41. Nguyen LK, Kolch W, Kholodenko BN. When ubiquitination meets phosphorylation: a systems biology perspective of EGFR/MAPK signalling. Cell Commun Signal. 2013;11:52.

42. Berndsen $C E$, Wolberger $C$. New insights into ubiquitin E3 ligase mechanism. Nat Struct Mol Biol. 2014;21:301-7.

43. Roskoski R Jr. Small molecule inhibitors targeting the EGFR/ErbB family of protein-tyrosine kinases in human cancers. Pharm Res. 2019;139:395-411.

44. Liu X, Teng Y, Wu X, Li Z, Bao B, Liu Y, et al. The E3 ubiquitin ligase Cbl-b predicts favorable prognosis in breast cancer. Front Oncol. 2020;10:695.
45. Kumar J, Kumar R, Kumar Singh A, Tsakem EL, Kathania M, Riese MJ, et al. Deletion of $\mathrm{Cbl}-\mathrm{b}$ inhibits $\mathrm{CD} 8(+) \mathrm{T}$-cell exhaustion and promotes CAR T-cell function. J Immunother Cancer 2021;9:e001688.

\section{AUTHOR CONTRIBUTIONS}

J.H., M.X., H.G., D.P., Y.L., P.H., H.C., and H.C. have participated in investigation, methodology and validation of data presented in this article. J.H., M.X., H.G., and D.P. are responsible for Formal Analysis of data. J.H. and M.X. wrote and edited this manuscript, and H.C. read and revised this manuscript.

\section{FUNDING}

This work was supported by the Natural Science Foundation of Chongqing (No. cstc2019jcyj-zdxmX0033 and No. cstc2020jcyj-msxmX0678), the National Natural Science Foundation of China (81872071 and 81672502), the Fundamental Research Funds for the Central Universities (SWU118097), and the Fundamental Research Funds for the Central Universities (XYDS201912).

\section{ETHICS APPROVAL AND CONSENT TO PARTICIPATE}

All experiments involving cancer patients' samples were obtained from Chaoying Biotechnology Co., Ltd. (Henan, China), and the studies were approved by the Medical Ethics Committee of Tongxu County People's Hospital of Henan Province. All of the patients were informed consent.

\section{COMPETING INTERESTS}

The authors declare no competing interests.

\section{ADDITIONAL INFORMATION}

Supplementary information The online version contains supplementary material available at https://doi.org/10.1038/s41419-021-04496-9.

Correspondence and requests for materials should be addressed to Hongjuan Cui.

Reprints and permission information is available at http://www.nature.com/ reprints

Publisher's note Springer Nature remains neutral with regard to jurisdictional claims in published maps and institutional affiliations.

\begin{abstract}
Open Access This article is licensed under a Creative Commons Attribution 4.0 International License, which permits use, sharing adaptation, distribution and reproduction in any medium or format, as long as you give appropriate credit to the original author(s) and the source, provide a link to the Creative Commons license, and indicate if changes were made. The images or other third party material in this article are included in the article's Creative Commons license, unless indicated otherwise in a credit line to the material. If material is not included in the article's Creative Commons license and your intended use is not permitted by statutory regulation or exceeds the permitted use, you will need to obtain permission directly from the copyright holder. To view a copy of this license, visit http://creativecommons. org/licenses/by/4.0/.
\end{abstract}

(c) The Author(s) 2022 